\title{
Cosmopolitan Interiors: Oscar Wilde and the House Beautiful
}

\author{
Deborah van der Plaat
}

In 1882, the Irish poet, writer and aesthete, Oscar Wilde (1854-1900) travelled to the United States and Canada to promote, in an early example of indirect marketing, the American showing of Gilbert and Sullivan's comic opera Patience. Funded by Richard D'Oyly Carte of the Savoy Opera Company, the highly recognisable Wilde was to educate the American public on the principles of aestheticism, a reference point for humour in Gilbert and Sullivan's opera (Gere and Hoskins 2000; Haill 2011). Travelling throughout America and Canada over a 10-month period, and lecturing in diverse and often unconventional venues, including the "Trimmed Hat Department" of the Eric Bros., Department Store in New York, Wilde delivered variations of four basic lectures: "The Renaissance in English Art", a presentation on the Pre-Raphaelites and the Grosvenor Gallery Artists, "Irish Poets and Poetry of the Nineteenth Century", "Art and the Handicraftsman" and "House Decoration". First delivered in Chicago in May 1882, the latter was later retitled the "House

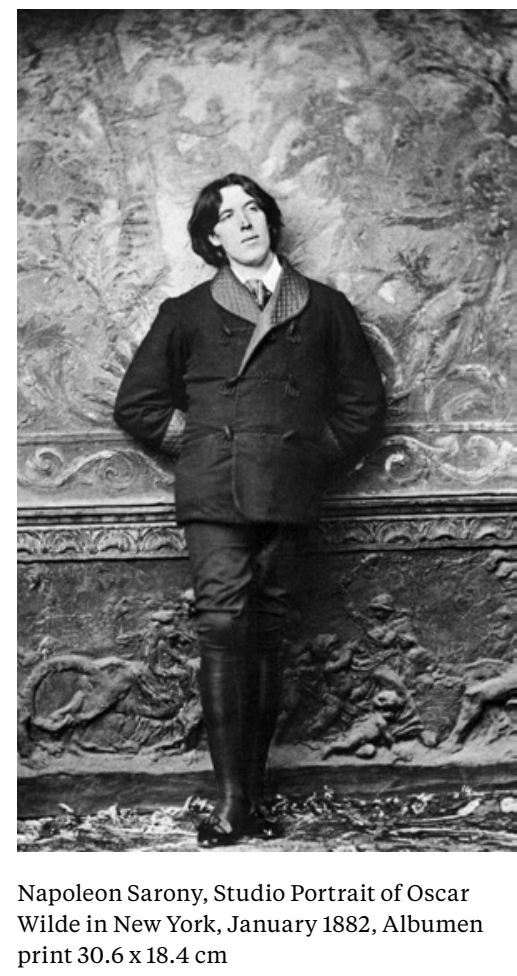

Kevin O'Brien has argued that Ross' edition of Wilde's lectures are incomplete, incorrectly titled, and misleading in that he failed to acknowledge that he was printing only the first version of "The English Renaissance", that his "Art and the Handicraftsmen" is the first version of "The Decorative Arts," and his "House Decoration" is a later version of the same lecture (O'Brien 1974:396).

2 O'Brien's reconstruction is based primarily on 'Oscar Wilde Lecture,' Montreal Daily Witness, 22 May 1882, 2.
Beautiful: The Practical Application of the Principles of Aesthetic Theory to Exterior and Interior House Decoration, with Observations upon Dress and Personal Ornaments" (Hofer \& Scharnhorst 2011; Gere \& Hoskins 2000). While Robert Ross, Wilde's literary executor, published the first two lectures in 1908, no manuscript of the latter has survived. ${ }^{1}$ A reconstruction of the text, however, based on first person reports in the American press of 1882, has been produced (O’Brien 1974). ${ }^{2}$

The aim of this paper is to consider how the lecture "The House Beautiful" unsettles existing conceptions of the aesthetic interior by focussing on Victorian theories of cosmopolitanism rather than an "Art for Art's sake" ethic. The importance of the lecture lay in its expansion of the conceptual intent of the House Beautiful beyond what Maureen Francis Moran has described as one of "self-culture" and 
"mind building" (2007: 292; Gere \& Hoskins 2000). It incorporated a broader critique of late nineteenth century nationalism and race politics. Metaphorically raising the blind on the late nineteenth century aesthetic interior, and conceptually linking it to an outside world, Wilde's lecture positions the interior as no longer the counterpart of, or retreat from, the global consciousness of Empire but as participating in a broader critique of cultural hierarchies and difference. Coupling ideals of cosmopolitanism to the aesthetic interior, the lecture also reveals Wilde's affinity with present day attempts to position cosmopolitanism as a conceptual method or process (Fine 2007; Platt 2009; Cheah 2006). At the same time, it offers a new rationale for late nineteenth century eclecticism and its use for both the aesthetic interior and the urban façade.

\section{The House Beautiful: A Lecture}

Wilde opened his lecture with a series of statements regarding the nature of Beauty (that which gives pleasure to both the maker and the observer), the ennobling qualities of art, the education of the worker and the problems of modern production (ideas indebted to the earlier writings of John Ruskin, 1818-1900, and William Morris, 1834-1896). He went on to identify a "general sameness" as the primary failing of the modern dwelling (HBL 401-2). "The first necessity of any system of art," he argued, was the "impress of a distinct individuality; ... every home should wear an individual air in all its furnishings and decorations". Such singularity could, however, function within "certain broad principles of art" (HBL 402-3). Considering these, somewhat prescriptively, Wilde described in some detail his vision of the ideal aesthetic interior. Starting with the entry hall, which should have a red tile floor, a hat rack and no pictures or stuffed animals under glass cases, Wilde then outlined the appropriate colour according to room type ("The problem with America", he concluded, "is the entire want of harmony or a definite scheme in colour"); the style of furniture to be used (Queen Anne); the treatment of ceilings (papered or painted); floor coverings (carpet squares, preferably from China, Persia and Japan); window size and colour (to avoid glare); lighting (a gas chandelier will "discolour and ruin all that you do"); the hanging of pictures (never in a row); the treatment of paintings (photographs are "libels on great masters"); the arrangement of flowers (never artificial or crowded together); the ornamentation of the mantle (with shelves to the ceiling for rare china ornaments); and the importance of old Japanese or Blue and White china (HBL 405-413). Suggesting the inclusion of "some good casts of old Greek work" and books ("an old library is one of the most beautifully colored things imaginable"), he concluded his commentary with the observation that "beautiful surroundings" should not be "marred" by "gloomy dress" (HBL 414).

Wilde's lecture appealed to his American audience. Ironically, it seems to have also undermined his reputation, and more broadly that of the aesthete, as indulgent and contrived - a persona his tour was intended to promote. One commentator, writing in the St John Daily Sun (Halifax, October 13, 1882), described Wilde's lecture as "honest" and went on:

The proper style of house decoration is dwelt upon in a thoroughly practical manner, - details of construction, painting, furnishing, decorating, heating and lighting abound; in short, the whole lecture is full of useful hints and suggestions, which will be readily appreciated and turned to account by the refined and beauty-loving housekeeper (Quoted in Snider 1940: 19) from O'Brien's (1974) reconstruction, unless stated otherwise. 


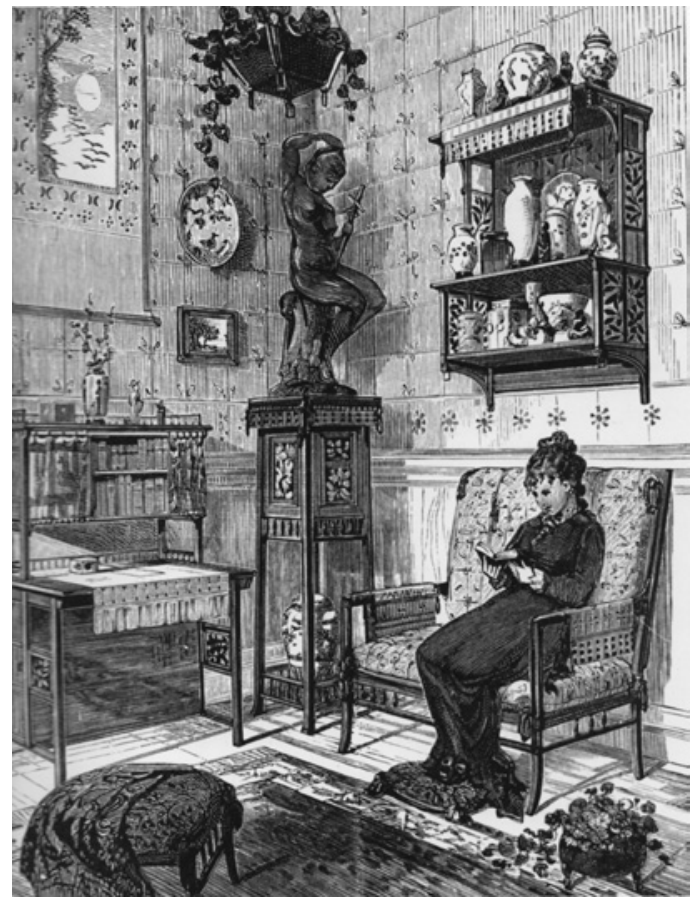

Alexandre Sandier, 'Much in a Little Space,' illustration from Clarence Cook The House Beautiful: Essays on Beds and Tables, Stools and Candlesticks, London, 1878

A second observer writing for The St John's Daily Telegraph (October 6, 1882) noted that the lecture examined such "serious questions as the conciliation of capital and labour" and "the elevation of the masses", and thereby revealed Wilde as "a man of a gentle and humane disposition, ... an admirer of the honest workman" rather than "a mere aesthetic trifler and a reputed snob ..." (quoted in Snider 1940: 16-17).

Many of the ideas that informed Wilde's lecture were not new and even well rehearsed by the 1880s. His debt to Ruskin and Morris has been described by some as “blatant plagiarism” (Gere \& Hoskins 2000: 88; O’Brien 1974: 400). The formal parallels between Wilde's lecture and the earlier decoration manual The House Beautiful (1878) by the American art critic Clarence Cook (1828-1900) has also been documented (Gere \& Hoskins 2007: 92). The wide appeal of these earlier sources offers some explanation for the accessibility of Wilde's ideas to his American audience. Yet within the lecture, Wilde introduced a series of interrelated themes that fall outside the discourses of Ruskin and Morris, as well as the practicality of the design manual. They remain largely unexamined until now. The first of these ideas is his consideration of the interrelationship between women and the decorative arts. Linking quality in the decorative arts to the status of women - arguing that "fine" and "delicate" work can only be produced when women are "highly honoured" and "occupy high social positions" - Wilde also claimed for the female gender a heightened aesthetic sensibility. ${ }^{4}$

It has been from the desire of women to beautify their households that decorative art has always received its impulse and encouragement. Women have natural instincts, which men usually acquire only after special training and study, and it may be the mission of the women of this country to revive decorative art into honest, healthy life. (Wilde quoted in O’Brien 1974: 40, note 14) 
Wilde aimed to locate an aesthetic sensibility and its acquisition, not in the traditional avenues of study and training, but in the everyday use of beautiful objects. Thereby, Wilde broadened the aesthetic project to include previously excluded groups: in the above instance, women. Later in the lecture, he seeks to incorporate the working class and non-western cultures. This was achieved by advocating a system of "practical instruction", in which young minds were no longer "burdened with long hours of study in the sciences and ... European history" (Lawrence T. Smyth reporting on the lecture "The Decorative Art", quoted in Snider 1940:11). Wilde, like many before him, linked the reformation of design to the collective display and study of diverse art forms from multiple eras, styles, and geographical regions. "An invaluable school of art" he suggested, would be:

... a museum, which, instead of showing stuffed giraffes and other horrible objects which scientific men wish to see gathered together, would contain all kinds of simple decorative work, different styles of furniture, dress, etc., made in different periods, and especially in the periods when English artists made beautiful things, and where local artisans and handicraftsmen could go and study the styles and patterns of the noble designers and artisans who worked before them. (HBL 410-11)

Such "efforts of cultivation" were illustrated, each Saturday night, "by the scene in the South Kensington museum ... where artisans [were] to be seen, notebook in hand, gathering ideas to be used in their next week's work," demonstrating that a good museum can "teach your artisans more in one year than they would learn by means of books or lectures in ten" (HBL 410-411). However, the ameliorative function of the decorative arts could, in Wilde's view, be extended beyond the workings of such an institution. Observing that the "handling of coarse objects begets coarse handling", Wilde also argued that the everyday use of beautiful objects had the potential to elevate skills and sensibilities. The "use [of] delicate things", he suggested, will "accustom your servants to handling them securely":

... it will be a martyrdom for a long time at first, but you may be content to suffer in so good a cause. I bought Venetian glass when I was at college, and for the first term my servant broke one glass every day, and a decanter on Sunday, but I persevered in buying them, and during the succeeding terms of my whole stay at college, he did not break a single piece. (HBL 412-13)

Linking class to race, Wilde observed how "in a restaurant in San Francisco a Chinese navvy [drank] his tea out of a most beautiful cup as delicate as the petal of a flower". Wilde commented that the "navvy", unlike his own servants, did not break the cup as he was "accustomed to handling" such fine porcelain. He also inverted the paradigm of improvement by noting that he himself, who "was staying in a first class hotel in which thousands of dollars was spent on gaudy colour and gilding" was forced to drink "out of a cup which was an inch and a half thick" (HBL 412-13). Challenging the exclusiveness of the aesthetic agenda - its middle to upper-middle class and Western orientation - Wilde also questioned the accepted cultural hierarchies of late Victorian Britain and their assumed patterns of improvement.

Wilde's conclusions built both upon the reforms put in place at South Kensington by Henry Cole and the Commissioners for the 1851 Exhibition (an institution driven by the dual objectives of skill and taste building, see Bonython \& Burton 2003; Hobhouse 2002) and the ideology of pleasure underpinning the doctrines 
of Ruskin and Morris. His linking of the above thesis of improvement to the representation of a "common intellectual atmosphere between all countries", however, is new (1882: 417). Wilde described such objectives in later writings as "cosmopolitanism" (1891a: 212) and thus revealed his debt to a broader Victorian discourse of cultivation and improvement centred on the liberal principles of "many-sidedness" and critical detachment (Thomas 2004, Anderson 2001). In doing so, he also offered new insight into the conceptual workings that underpinned his aesthetic ideal: an analogical process of comparison and contrast motivated by the desire to identify sameness across difference. Further, he suggested a new rationale for the eclectic flavour of the late nineteenth century aesthetic interior and its urban façade.

\section{Cosmopolitanism}

In his 1882 lecture, Wilde also challenged the view that the aesthetic movement sought to disassociate art from a moral function and located art's morality in its ability to build intellectual bonds across multiple cultures.

Wars and the clash of arms and the meeting of men in battle must be always, but I think that art, by creating a common intellectual atmosphere between all countries might, if it could not overshadow the world with silvery wings of peace, at least make men such brothers that they would not go out to slay one another for the whim or folly of some king or minister as they do in Europe: for national hatreds are always strongest where culture is lowest. (HBL 417)

Revisiting this theme in his later essay, "The Critic as Artist" (1891), and noting that it is "only by cultivation of the habit of intellectual criticism that we shall be able to rise superior to race prejudices," Wilde labelled this phenomenon within art as "cosmopolitanism".

This note, sounded in the modern world by Goethe first, will become, I think, the starting point for the cosmopolitanism of the future. Criticism will annihilate race prejudices, by insisting upon the unity of the human mind in the variety of its forms. If we are tempted to make war upon another nation, we shall remember that we are seeking to destroy an element of our own culture, and possibly its most important element. As long as war is regarded as wicked, it will always have its fascination. When it is looked upon as vulgar, it will cease to be popular. (Wilde 1891a: 212)

To be cosmopolitan in mid to late nineteenth century England, as David Wayne Thomas (2004) and Amanda Anderson (2001) argue, was to believe in an alternative mode of artistic agency that was no longer restricted to the romantic notion of genius but accessible to a wider audience. Central to this ethic, according to both authors, was the cultivation of an ambivalent disposition, a detachment or distance from one's own culture. As Thomas suggests, what distinguishes Victorian "manysidedness", or cosmopolitanism, within the broader discourse of liberal agency was the idea of "plural forms of life". This subjectivity took up "a critical position from which various positions - even positioning in general - can be thought".

To declare a place in that habitat is to lay claim to what ... is a distinctly liberal aspiration to many-sidedness, a vision to which [the English essayist Walter] Pater has it 'all the ends of the world are a matter of interest and concern'. (2004: 47) 
The advantages of such a disposition were threefold. Firstly, it enabled a cultivated distance from one's own culture, encouraging critical reflection, judgement and potentially improvement (Anderson 2001: 61-63). Secondly, the occupation of dual or multiple 'lives' made explicit intellectual and aesthetic processes that have subsequently been described by scholars as synecdochic: the particular and local are positioned as indices of the common (Thomas 2004, Bullen 1992; Connor 1989). Finally, Victorian many-sidedness identified a tempered subjectivity that was seen to be genuinely democratic and accessible to those lacking genius, a group previously excluded by romantic definitions of artistic agency. The emergence of this alternate sensibility, Thomas argues, is evident in John Stuart Mill's On Liberty (1859), where an "incessant oscillation between two antithetical values" is enacted:

... on the one hand, a vision of genius, understood as a heroics of individuality; and on the other, a practice of liberal many-sidedness, a kind of tolerance and cosmopolitanism that had to be understood itself as another kind of accomplishment”. (Thomas 2004: 33)

Several of these ideas appear to inform Wilde's understanding of cosmopolitanism. Like the broader Victorian debate, his thesis is grounded in a larger discourse on cultivation and self-improvement. Writing that "self-culture is the true idea of man" (an idea he again attributed to Goethe) and that the "English race was a degraded one - sunk under a mess of facts", Wilde also argued that the only action that could improve this situation was the "growth of the critical instinct" (1891a: 180 \& 209, 1891b: 19). In his earlier lecture on the "House Beautiful", this idea was made explicit by the ameliorative function of the beautiful object - Venetian glass or Blue and White china - and its capacity to foster across gender, class and race a heightened aesthetic sensibility.

Importantly, the operation of such a function appears for Wilde to have been based on synecdochic or analogical processes. This is suggested by his identification of Plato as the source for such thinking in his writings. Drawing on Plato's observation that the true aim of education was "the love of beauty", and that the best methods to achieve this were the "development of temperament, the cultivation of taste, and the creation of a critical spirit", Wilde also repeated Plato's conviction that such processes were intimately linked to the beauty of one's physical surroundings.

[Raised in the midst of] fair sights and sounds ... there is to be engendered ... such a temperament as will lead him naturally and simply to choose the good in preference to the bad, and, rejecting what is vulgar and discordant, to follow by fine instinctive taste all that possesses grace and charm and loveliness. Ultimately, in its due course, this taste is to become critical and self-conscious, but at first it is to exist purely as cultivated instinct ... and with a taste that cannot err while he praises, and finds his pleasure in what is good, and receives it into his soul, and so becomes good and noble, he will rightly blame and hate the bad ... (Wilde 1891a: 194-5)

Barbara Maria Stafford, in Visual Analogy, Consciousness and the Art of Connecting (2001), explains how Plato's thesis of education is determined by the ancient ideal of participatory analogy. In contrast to proportional analogy (a method based "on establishing quantitative proportions using a geometrical language of equality and inequality") the rhetoric of participation "employed a mimetic vocabulary of similarity and dissimilarity" (2-3). Stafford identifies the latter specifically with Plato, who "declared that analogy was the most beautiful bond possible", and 
goes on to describe analogy as a "metaphoric and metamorphic practice for weaving discordant particulars into a partial concordance" that "spurs the imagination to discover similarities in dissimilarities". Importantly though, and in direct contrast to the practices of allegory or metaphor proper, analogy at the same time avoids the "subsumption of two inferior, dichotomous terms into a superior third" by continuing to acknowledge difference (8-9). She further suggests that participatory analogy is celebrated by Plato in the Timaeus (29-30) and the Republic (472 b-e), where he develops the notion of an "image sharing or partaking in a pattern". Stafford argues that for Plato participatory analogy represented both a "metaphysics and a logic, a vision and a form of reasoning that allows us to infer the ontological and phenomenological likenesses binding seemingly unrelated things” (89).

It is important to recognise the contribution of Plato to Wilde's thesis, as it offers some insight into his understanding of cosmopolitanism. Seeking visual connections across multiple design traditions, analogy offered a ready tool for establishing a common intellectual atmosphere across multiple cultures. That he avoided synthesis through a continued acknowledgement of difference also demonstrated his positioning of cosmopolitanism within an intellectual process, rather than a fixed style or material outcome. In negotiating the dual poles of similarity and difference, Wilde prezured present day attempts to define (new] cosmopolitanism as a "both-and", rather than an "either-or" process (Platt 2009; Fine 2007; Cheah 2006). More pragmatically, however, it opens up new interpretations of what has been described as the "oppositional eclectics" of the aesthetic interior. In her paper on the Oxford poet and painter Walter Pater (1839-1894), which draws on author Mary Ward's 1870s description of Pater's home, Moran observes the coming together of objects within the aesthetic interior: Morris wallpaper, spindle-legged tables and chairs, blue plates and pots from Holland, framed embroidery, engravings by Renaissance artists and simple flower arrangements. Moran sees a deliberate attempt here to set up a careful juxtaposition of the natural and the artificial, the medieval and Renaissance, and the handmade with the mass-produced. She argues that such displays announced for the Oxford intellectuals a new art of discrimination and their rejection of the "overstuffed values of mid-Victorian design" (2007: 291). Moran also draws parallels between Pater's literary descriptions of the House Beautiful and the environmental determinism of the 'genetic' psychologist James Sully (1842-1923), who argued "the contents and order of arrangements of environments ... determine the form of our mental life", and links such arrangements to nineteenth century theories of mental progress (Moran 2007: 295).

Taking into account Wilde's interest in Plato and, by extension, analogy, gives rise to some additional insights or questions into the mental life that was intended for the occupant of the aesthetic interior. For instance, was this oppositional display intended to have a cosmopolitan function, to encourage an intellectual process that mapped sameness and difference across a diverse range of objects?

Support for such a suggestion is importantly found in Wilde's simultaneous alignment of critical temperament and aesthetic sensibility with common or universal values and the recognition of their dependency on an intellectual and emotional stance that is many-sided, multi-dimensional and complex. Wilde suggests the role of the critic is to "distil... into finer essence" the "cumbersome mass of creative works" and to identify the thread that will "guide" one through such material (Wilde 1891a: 210). He also stresses how important it is for the critic to accommodate multiple viewpoints. Unlike the artist, who is unable to escape his own mode of production (a quality which disqualifies the artist from the act of criticism; 1891a: 185-6), Wilde's critic must occupy multiple lives and view points at any one time, 
be they defined by categories of race, place or time. Because the development of the critical spirit was dependent not only on an understanding of the nineteenth century, but also of "every century which preceded it," and because to "know oneself, one must know about all others," Wilde also insisted that the critic must empathise with the art of all ages and places. "There must be no mood with which one cannot sympathize, no dead mode of life that one cannot make alive". (Wilde 1891a: $172-3)$

For Wilde, a formal device for achieving this weaving of "discordant particulars" (decorative artefacts) into partial concordance was the use of keynote colour. This had the advantage of integrating the various features of a room, including its decorative artefacts, into "a harmonious whole" ("it must be decided beforehand what scheme of colour is desired and have all else adapted to it”; Wilde 1882: 405). The use of a keynote colour also opened the room to a multitude of readings: "Mere colour, unspoiled by meaning, and unallied with definite form can speak to the soul in a thousand different ways.” (Wilde 1891a: 147-8)

\section{Cosmopolitan exteriors}

If we accept Wilde's argument that the moral function of the House Beautiful interior lies in its cosmopolitan function - its fostering of a "common intellectual atmosphere", using a vocabulary of sameness and difference - we are also forced to rethink the inward-looking ideal of self-culture that is more commonly associated with it. Wilde's thesis of cosmopolitanism does not negate such objectives within the aesthetic interior. In fact, he supports a central thesis of cultivation and self-improvement, but he expands its concerns beyond the containment of the domestic interior and its occupants (primarily women and children), inverting these outward to an exterior world of national politics, racial prejudice and conflict. The occupant of Wilde's aesthetic interior is not only required to cultivate an aesthetic sensibility critical of existing design norms but also to develop a new empathy for aesthetic cultures other than her own.

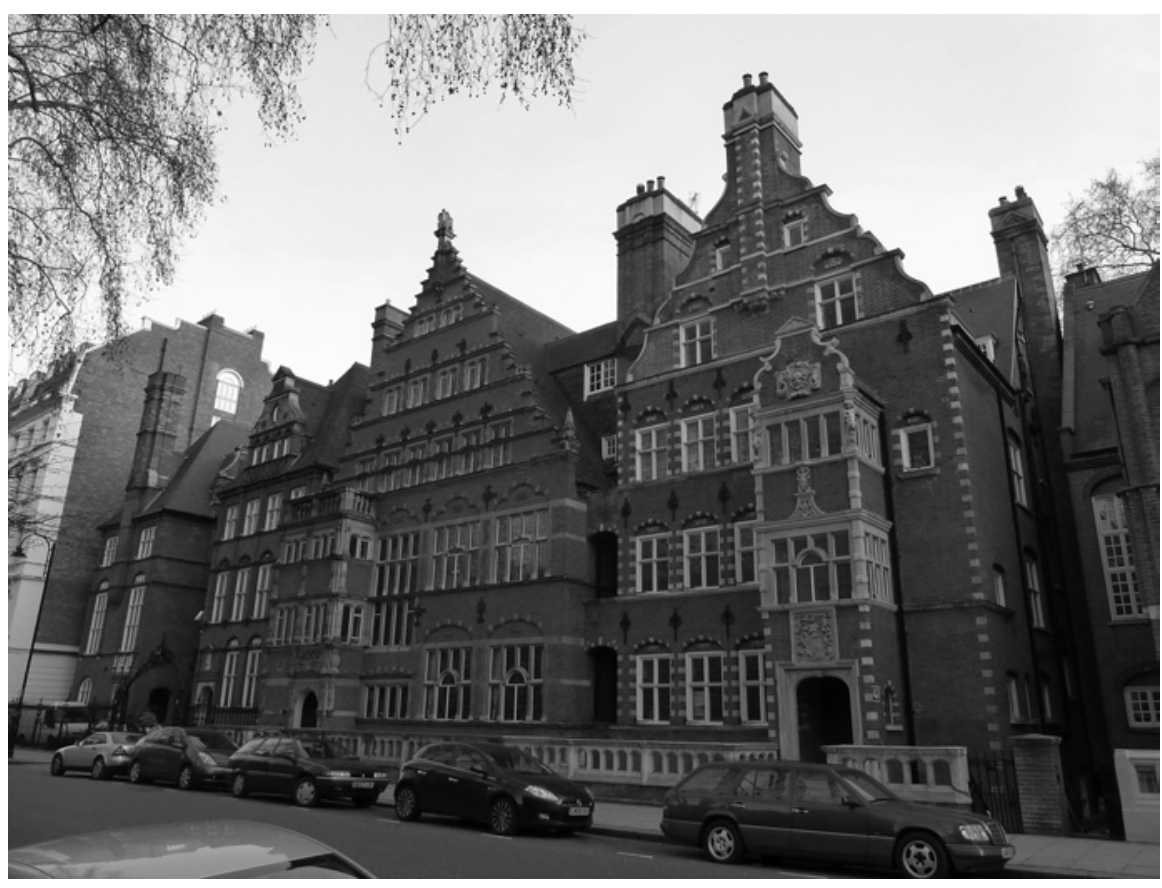

Nos. 35-45 Harrington Gardens, SouthWest Kensington, 1882-85. No. 39 (with crowning detail of sailing ship and sea monsters) for W.S. Gilbert (of Gilbert and Sullivan). Photo: Gordon Wong, 2011 
While the attachment of cosmopolitanism to Wilde's understanding of the House Beautiful lifts the blinds, so to speak, on the aesthetic interior by suggesting new links between it and the outside world, these relationships were not solely conceptual. Remember the full title of Wilde's 1882 lecture: "House Beautiful: The Practical Application of the Principles of Aesthetic Theory to Exterior and Interior House Decoration, with Observations upon Dress and Personal Ornaments" (Gere \& Hoskins 2000: 12). Including the exterior of the house within the reach of his lecture, Wilde spent a significant portion of his lecture time dealing with the preferred materials, colours and ornamentation of the urban façade. As with his consideration of the interior, his suggestions are often straightforward and practical. First, he dealt with materials and described the appropriate and best use of marble, stone, wood and brick. If marble is to be used, it should not be treated like ordinary stone as a "mere building block", a practice that produces "great, plain and staring white structures". Instead, "I hope you will employ workmen competent to beautify it with delicate tracings and that you will have it beautifully inlaid with colour marbles, as at Venice, to lend it colour and warmth.” Turning to the use of stone, Wilde encouraged his audience to take advantage of the "natural hues" that could be found in America, "from pale yellow to purples, red to orange, [and] green to grey and white". "Ingraining them" would produce "beautiful harmonies" (Wilde 1882: 403-404). When marble or coloured stones were unavailable, there remained the option of red brick or wood. Wilde identified wood as a "universal material" and discouraged Americans from painting their houses white or grey: both "are dreary in wet weather and glaring in fine". Rather, warmer colours, "the rich browns and olive greens found in nature", should be used. In a manner reminiscent of the stone or marble house, enriched with ingraining and carved tracery, the wooden house should also be made "more joyous to look upon with the aid of the carver". Red brick, "which is warm and delightful to look at, and a simple form for those who do not have too much to spend", was the fourth material considered. An advantage of the cut brick, Wilde observed, is that it "gives you the opportunity of working in terracotta ornamentation, the most beautiful of all exterior decorations - the old Lombard's special pride, and an art we are trying to revive in England". He strongly suggested that all exterior ornament should be "carved" and not cast or machine-made and concluded his discussion of the exterior with the proposition that the common use of the "black-lead [door] knocker should give way to a bright brass one" (Wilde 1882: 404).

The house exterior evoked by Wilde, of coloured variety, carved tracery, ornament, and juxtaposed materials (inlaid marbles, ingrained stone or red brick and Lombardic terracotta), reflects the growing visual complexity and eclecticism of the urban façade in London of the 1880s. This eclecticism actively challenged the monochrome and often monotonous Italianate façades of the city's terrace housing, as demonstrated by the houses of Richard Norman Shaw (1831-1912), Philip Webb (1831-1915), Edward Godwin (1833-1886) and George Aitchison (1825-1910) (Saint 1976; Kirk 2005; Service 1975; Gere 2010a \& b). Yet, Wilde's discussion of the house exterior also suggests another meaning. His reference to the inlaid marbles of Venice, together with the terracotta ornamentation of the Lombard ("a tradition currently undergoing a revival in England"), is reminiscent of John Ruskin's earlier and well-known discussion of the Ducal Palace in the Stones of Venice. Described by Ruskin as "the central building of the world", the palace represented the accommodation of multiple design cultures, of "Roman, Lombard and Arab", within a single building (Ruskin in Cook and Wedderburn, 1903-12: vol.9, 38). Mark Crinson argues that Ruskin, acquainted with the idea of Italy as "a stage" for racial struggle and with the aid of a geological metaphor, developed in his reading of the Palace the notion of "racial mixture or hybridity as the very source of architectural 
achievement". An infusing and enrichment of cultures, where the "lava stream of the Arab ... warmed ... the Northern air", the history of Gothic architecture in Venice is conceived by Ruskin as "one of refinement and spiritualisation of Northern work under [a southern or Arab] influence”. Ruskin wrote his interpretation of the Ducal Palace at a time when his view of Islamic culture was positive. It not only presents, as Crinson observes, such racial and design juxtapositions (a cosmopolitanism perhaps) as productive, it also countered the often "violent dialectic of Aryan and Semite” more common in Victorian thinking (Crinson 1996: 51-53).

Such ideas, I assume, must have appealed to Wilde's interests in cosmopolitanism. More importantly, they also offered him architectural concepts - the harmonious discord of juxtaposed colour, materials, and styles - to externally articulate the critical strategies of cosmopolitanism. Inverting the container of the House Beautiful, both conceptually and materially, allowed him to read the urban façade not only, to borrow Moran's words, as a "mark of civilisation" but also as an intellectual "method" (Moran 2007: 292): a process that motivated the observer to mentally map the similarities and differences binding (or separating) architectural traditions over time and place.

Linking the House Beautiful to ideals of cosmopolitanism, Wilde also associated the aesthetic interior with a broader discourse of cultivation and improvement that sought to identify an intellectual atmosphere common to all cultures. In doing so, he conceptually challenged the sole association of such spaces with (feminine) domesticity and self-culture and reconnected them to an exterior and (masculine) world concerned with politics, trade, nation states and race relations. Drawing on Plato's ideas of education and beauty and, by extension, analogy, Wilde demonstrated his intent to identify not only what is universal and common, but also to map similarity and difference. This observation offers new insight into Wilde's understanding of a cosmopolitanism centred on process and method - a mode of reasoning and negotiation, rather than fixed form or style. It also offers opportunities to reread the eclecticism of the aesthetic interior. Finally, by offering detailed descriptions in his American lecture on the exterior decoration of the House Beautiful, Wilde suggested that such concerns apply not only to the aesthetic interior but extend to the urban façade. It is perhaps in this final point that the true extent of Wilde's cosmopolitan project can begin to be appreciated.

\section{References}

Anderson, A. (2001). The Powers of Distance. Cosmopolitanism and the Cultivation of Detachment. Princeton \& Oxford: Princeton University Press.

Bonython, E., \& Burton, A. (2003). The Great Exhibitor. The Life and Work of Henry Cole. London V\&A Publications.

Bullen, J. B. (1992). Ruskin and the Tradition of Renaissance Historiography. In M. Wheeler \& N. Whitely (Eds.), The Lamp of Memory: Ruskin, Tradition, and Architecture. Manchester: Manchester University Press, 54-76.

Cheah, P. (2006). Cosmopolitanism. Theory, Culture and Society, 23, 486-496.

Connor, S. (1989). Conclusion: Myth and Meta-myth in Max Muller and Walter Pater. In J. B. Bullen (Ed.), The Sun is God: Painting, Literature and Mythology in the Nineteenth Century. Oxford: Oxford University Press.

Cook, C. (1878). The House Beautiful: Essays on Beds and Tables, Stools and Candlesticks. New York.

Cook, E. T., \& Wedderburn, A. (Eds.). (1903-12). The Collected Work of John Ruskin. London: George Allen.

Crinson, M. (1996). Empire Building: Orientalism \& Victorian Architecture.

London \& New York: Routledge. 
Dowling, L. C. (1996). The vulgarization of art: the Victorians and aesthetic democracy. Charlottesville, Va.: University Press of Virginia.

Fine, R. (2007). Cosmopolitanism. New York: Routledge.

Gere, C. (2010a). Artistic Circles: Design and Decoration in the Aesthetic Movement. London: $\mathrm{V} \& A$ Publishing

Gere, C. (2010b). Three Artists' Studio-Houses in London: for Leighton, Millais and Alma Tadema. In D. Robbins (Ed.), Closer to Home: The Restoration of Leighton House and Catalogue of the Reopening Displays, 2010 (pp. 6-13). London: The Royal Borough of Kensington and Chelsea.

Gere, C., \& Hoskins, L. (2000). The House Beautiful: Oscar Wilde and the Aesthetic Interior. London: Lund Humphries and Geffrye Museum.

Haill, C. (2011). 'Patience' and the Theatre. In S. Calloway, L. F. Orr \& E. Whittaker (Eds.), The Cult of Beauty. The Aesthetic Movement 1860-1900 (pp. 220-221). London: V\&A Publishing

Hobhouse, H. (2002). The Crystal Palace and the Great Exhibition. Art, Science and Productive History. A History of the Royal Commission for the Exhibition of 1851. London and New York: Continuum.

Hofer, M., \& Scharnhorst, G. (Eds.). (2010). Oscar Wilde in America. The Interviews. Urbana and Chicago: University of Illinois Press.

Kirk, S., Webb, P., \& Charles, M. (2005). Philip Webb : pioneer of arts \& crafts architecture. Chichester: Wiley-Academy.

Moran, M. F. (2007). Walter Pater's House Beautiful and the Psychology of Self -Culture. English Literature in Transition, 50(3), 291-312.

Mill, J.S. (1859). On Liberty. London: John W. Parker \& Son.

O’Brien, K. H. F. (1974). “The House Beautiful”: A reconstruction of Oscar Wilde's American Lecture. Victorian Studies, 17(4), 395-418.

Platt, A. (2009). Cosmopolitanism, by Robert Fine (a review). Contemporary Sociology: A Journal of Reviews, 38, 78-79.

Ross, R. (Ed.). (1908). The Collected Works of Oscar Wilde. London: Methuen \& Co.

Service, A. (1975). Edwardian architecture and its origins. London: Architectural Press.

Shedd, W. G. T. (Ed.). (1871-1875). The Complete Works of Samuel Taylor Coleridge New York: Harper Bros.

Snider, R. (1940). Wilde's Progress down East. The New England Quarterly, 13(1), 7-23.

Stafford, B. M. (2001). Visual Analogy: Consciousness as the Art of Connecting. Cambridge: MIT Press.

Sully, J. (1889). Outlines of Psychology with special reference to the theory of education (6th ed.). London: Longmans, Green \& Co.

Thomas, D. W. (2004). Cultivating Victorians: Liberal Culture and the Aesthetic. Philadelphia: University of Pennsylvania Press.

Wilde, O. (1891a). The Critic as Artist. Intentions (pp. 95-217). New York: Prometheus Books.

Wilde, O. (1891b). The Decay of Lying. Intentions (pp. 3-55). New York: Prometheus Books. 